\title{
Somatostatinoma: Beyond neurofibromatosis type 1 (Review)
}

\author{
FLORICA SANDRU $^{1,2}$, MARA CARSOTE $^{3,4}$, ANA VALEA $^{5,6}$, SIMONA ELENA ALBU $^{7,8}$, \\ RĂZVAN-COSMIN PETCA ${ }^{9}$ and MIHAI CRISTIAN DUMITRASCU ${ }^{7,8}$
}

\author{
${ }^{1}$ Department of Dermatology, 'Elias’ Emergency University Hospital, 125100 Bucharest; ${ }^{2}$ Department of Dermatology, \\ 'Carol Davila' University of Medicine and Pharmacy, 020021 Bucharest; ${ }^{3}$ Department of Endocrinology, 'C.I. Parhon' \\ National Institute of Endocrinology, 011863 Bucharest; ${ }^{4}$ Department of Endocrinology, \\ 'Carol Davila' University of Medicine and Pharmacy, 020021 Bucharest; ${ }^{5}$ Department of Endocrinology, Clinical County \\ Hospital, 400000 Cluj-Napoca; ${ }^{6}$ Department of Endocrinology, 'Iuliu Hatieganu' University of Medicine \\ and Pharmacy, 400012 Cluj-Napoca; ${ }^{7}$ Department of Gynecology, Emergency University Hospital, 050098 Bucharest; \\ ${ }^{8}$ Department of Gynecology, 'Carol Davila' University of Medicine and Pharmacy, 020021 Bucharest; \\ ${ }^{9}$ Deparment of Urology, 'Prof. Dr. Theodor Burghele' Clinical Hospital, 925200 Bucharest, Romania
}

Received April 10, 2020; Accepted May 13, 2020

DOI: $10.3892 / \mathrm{etm} .2020 .8965$

\begin{abstract}
Somatostatinoma is a tumour mainly originating from pancreas or duodenum; overall with an incidence of $1 / 40$ million persons. We introduce a narrative review of literature of somatostatinoma including the relationship with neurofibromatosis type 1 . Clinical presentation includes: Diabetes mellitus, cholelithiasis, steatorrhea, abdominal pain, and obstructive jaundice while papillary tumour may cause acute pancreatitis. The neoplasia may develop completely asymptomatic or it is detected as an incidental finding during an imaging or a surgical procedure. It may be sporadic or associated to genetic backgrounds especially for duodenal localisation as neurofibromatosis type 1 (NF1 gene with malfunction of RAS/MAPK pathway) or Pacak-Zhuang syndrome (EPASI gene encoding HIF). Surgery represents the central approach if feasible but the prognostic depends on location, and grading as indicated by WHO 2017 classification of neuroendocrine tumours. Previously known as Von Recklinghausen disease, neurofibromatosis type 1 , the
\end{abstract}

Correspondence to: Dr Ana Valea, Department of Endocrinology, Clinical County Hospital, 3-5 Clinicilor Street, 400000 Cluj-Napoca, Romania

E-mail: ana74us@yahoo.com

Abbreviations: ACTH, adrenocorticotropic hormone; CCK, cholecystokinin; ${ }^{68} \mathrm{Ga}$, gallium; GIST, gastrointestinal stromal tumours; HIF2A, hypoxia-inducible factor; NGS, next-generation sequencing; pNEN, pancreatic neuroendocrine neoplasia; PET, positronic emission tomography; PRRT, peptide receptor radionuclide therapy; SR, somatostatin receptors; SSA, somatostatin analogues; SRI, somatostatin receptor imaging; $\mathrm{TSH}$, thyroid stimulating hormone

Key words: somatostatinoma, neurofibromatosis, somatostatin, neuroendocrine, duodenal tumour most frequent neurocutaneous syndrome, is an autosomal dominant disorder including: Café-au-lait spot, skin fold freckling on flexural zones, and neurofibromas as well as tumours such as gliomas of optic nerve, gastrointestinal stromal tumours (GISTs), iris hamartomas and brain tumours. Duodenal somatostatinoma is associated with the syndrome which actually involves more often a duodenal tumour of GIST type than a somatostatin secreting neoplasia. Other neuroendocrine tumours are reported: Gastrointestinal NENs at the level of rectum or jejunum and pheocromocytoma. Overall, one quarter of subjects have gastrointestinal tumours of different types. Somatostatinoma, when not located on pancreas but in duodenoum, may be registered in subjects with neurofibromatosis type 1 most probably in addition to other tumours. Overall, this type of neuroendocrine tumour with a challenging presentation has a poor prognosis unless adequate radical surgery is promptly offered to the patient.

\section{Contents}

1. Introduction

2. Method

3. Pancreatic neuroendocrine neoplasia

4. Somatostatin: A general perspective

5. Somatostatin secreting tumours

6. Neurofibromatosis type 1

7. Somatostatinoma and neurofibromatosis type 1

8. Discussion

9. Conclusions

\section{Introduction}

Somatostatinoma is a tumour mainly originating from two organs: On the one hand are the $\delta$ cells of the pancreas which produce somatostatin, being a part of pancreatic neuroendocrine neoplasia (pNEN), and on the other hand, there is the 
duodenum source; overall with an incidence of $1 / 40$ million persons (1). Clinical presentation includes diabetes mellitus, cholelithiasis, steatorrhea, abdominal pain, vague symptoms, and some describe the specific triad as: Glucose metabolism anomalies, steatorrhea and aclorhydria $(2,3)$. Hypoglycemia also has been reported potentially related to insulin co-secretion from pancreas tumour or as a functional release (3). Obstructive jaundice is caused by masses located at the level of ampulla of Vater, and papillary tumour may also cause acute pancreatitis (including repetitive episodes) $(4,5)$. However, the neoplasia may develop completely asymptomatic or it may be detected as an incidental finding during an imaging technique of an endocrine/non-endocrine organ or during a surgical procedure for abdominal pain of unknown cause or other non-related synchronous conditions $(2,6,7)$. The tumour may be sporadic or associated to different genetic backgrounds as neurofibromatosis type 1 for duodenal localisation (8). Blood somatostatin assays as well as others less specific neuroendocrine markers such as chromogranin A or neuron specific enolase are useful for initial diagnosis but also as prognostic parameters during follow-up (9). The hormonal excess is similar between pancreatic and duodenal localisations, but the admission may be due to local compressive symptoms because of the tumour mass itself $(2,6,7)$. The immunostain for somatostatin confirms the diagnosis, noting that many cases may have a silent evolution or associate local non-specific symptoms and thus the post-operative histological and immunohistochemical report is crucial for adequate disease recognition (10). Surgery such as pancreatico-duodenectomy represents the central element of approach if feasible but the prognostic depends on location, and grading as pointed out by WHO 2017 classification of neuroendocrine tumours $(8,10)$.

\section{Method}

Our aim was to introduce a narrative review of literature of somatostatinoma, also stressing the relationship with neurofibromatosis type 1 . The data research used mostly PubMed database, and a selection of 57 articles was included.

\section{Pancreatic neuroendocrine neoplasia}

pNENs might produce glucagon, insulin, gastrin (causing Zollinger-Elison syndrome), vasoactive intestinal polypeptide (VIP), rarely calcitonin, serotonin, adrenocorticotropic hormone (ACTH) and, recently, cholecystokinin (CCK)-oma syndrome has been reported considering the tumour-related production of CCK $(11,12)$. Somatostatinoma represents $5 \%$ of pNENs thus it is one of the rarest pathological secretions of the pancreas (13). Both pNEN and gastrointestinal NEN are the main group of NENs $(11,12)$. They all have the capacity to produce specific and non-specific neuroendocrine markers/hormones and to express somatostatin receptors (SR) which are targeted by somatostatin analogues (SSA) $(11,12)$. The main line of therapy for pNENs is surgery with curative intention or, in severe cases, there is a need for debulking procedure involving the primary lesion and/or metastasis such as hepatic metastasis in association with medical therapy (depending of grading, tumour size and site, and histological profile) as well as peptide receptor radionuclide therapy (PRRT) especially for NENs with a poor level of differentiation (14).

\section{Somatostatin: A general perspective}

Somatostatin of pancreatic/duodenal origin is a hormone with a biochemical structure of tetradecapeptide (15). It inhibits exocrine and endocrine functions such as gut and pancreatic hormones, but also intestinal motility and local nutrients absorption, and gastric acid secretion (15). Pancreatic $\delta$ cells exhibit paracrine actions of $\beta$ and $\alpha$ cells especially with the purpose of glucose regulation (16). Central somatostatin is produced by hypothalamus and it displays also inhibitory effects on pituitary growth hormone, thyroid stimulating hormone (TSH) and prolactin (17). SRs are widespread in the brain and their activation communicates with the modulation of food and water intake and recently they have been linked with obesity pathogenesis (17-19). Further innovative approaches of obesity are currently under development and they include anti-obesity vaccines with hormone analogues such as somatostatin or ghrelin (20).

\section{Somatostatin secreting tumours}

Pancreas site is involved in $70 \%$ of all the somatostatin producing tumours (36\% at head level, $14 \%$ at the body, and $32 \%$ at the pancreatic tail) in addition to $19 \%$ at the duodenum area, $3 \%$ at ampulla of Vater, and 3\% at small bowel, while exceptional localisations at pulmonary area, thyroid lobes or renal parenchyma have been reported (21-23). Gastric location complicated with gastrointestinal bleeding is also uncommon (24).

Somatostatinoma has been reported in association with genetic conditions. For instance, polycythemia-paraganglioma-somatostatinoma syndrome (also called Pacak-Zhuang syndrome) is a very rare underlying paraganglioma/pheocromocytoma and somatostatin producing tumour (mostly of duodenal origin) in addition to the mentioned haematological disorder in children and mutations such as EPASI gene encoding hypoxia-inducible factor (HIF2A) or von Hipple-Lindau gene (25-27). Recently the gain of function involving the mutation of EPAS1 gene (oxygen degradation domain) has been identified as aetiology of the Pacak-Zhuang syndrome (28). Moreover, non-mosaicism somatic mutations of HIF2A seem to induce the same syndrome but with late onset (29).

Somatostatinoma syndrome includes: Diabetes mellitus, diarrhoea and gallstones (30-32). Less frequently other features are found such as hypochlorhydria/achlorhydria, dyspepsia and weight loss (30). These are caused by inhibitory effects of the somatostatin on the other pancreatic hormones including insulin or on gastrointestinal parameters as gastric acid secretion $(1,30)$. Duodenal location of the somatostatinoma causes anaemia and gastrointestinal haemorrhage (30-33).

Increased blood levels of somatostatin are found in different amounts depending on tumour production (30). Neuroendocrine markers that are less specific such as chromogranin A, neurron specific enolase, and 5-hydroxytryptamine might help the diagnosis and follow-up $(30,31,34)$. Imaging techniques are widely variable such as ultrasound, computed tomography, magnetic resonance imagery, positronic emission 
tomography (PET), and somatostatin receptor imaging (SRI) such as octreoscan $/{ }^{68} \mathrm{Ga}$ (Gallium)-DOTATATE $(30,35)$. Immunohistochemistry in somatostatinomas is positive for somatostatin and also for chromogranin A and synaptophysin as hallmark of the neuroendocrine component $(36,37)$. Non-specific somatostatin assay is also found in medullar thyroid cancer and pheocromocytoma (30). Somatostatinomas are positive for SR type 2 and 5 out of the five SR types (30).

Surgery is the only option with curative intention and techniques such as partial/total pancreatectomy, duodenectomy, pancreaticoduodenectomy, cholecystectomy, endoscopic papillectomy are used $(30,33)$. However surgery is not feasible in many cases because of the tumour anatomy or rapid invasion or because of deteriorated clinical status, delayed diagnosis (30). SSAs such as octreotide or lanrerotide exhibit both tumour and hormonal control $(30,37)$. In addition to SSAs, PRRT like ${ }^{177}$ Lu-DOTATATE may improve the poor survival while thyosine kinase inhibitors express a certain response (38). However, the current standard management is still far from optimal.

\section{Neurofibromatosis type 1}

Previously known as Von Recklinghausen disease, neurofibromatosis type 1 , the most frequent neuro-cutaneous syndrome, is an autosomal dominant condition [mutations of neurofibromatosis type 1 (NF1) gene] with a relative high frequency in general population (for a genetic disorder) $(39,40)$. The reported incidence is $1 / 2500-1 / 3000(39,40)$. The mutation causing the condition is at the level of NF1 gene (on chromosome 17) which induces a malfunction of RAS/MAPK (known as Ras-Raf-MEK-ERK) pathway since normally neurofibromin down-regulates RAS expression (41). Somatic mutations of the same gene have been found in non-syndromic cancers such as melanoma as well as in chemotherapic resistance for various neoplasia (41).

The skin lesions are café-au-lait spots (or macules), and neurofibromas which are both benign $(40,41)$. Their clinical recognition is enough for diagnosis based on three aspects: Café-au-lait spots, skin fold freckling on flexural zones, and neurofibromas (which have the best positive prediction) (42). Lipomatous neurofibroma is a variant of neurofibromas containing an increased number of adipocytes, being more frequent in females and in larger neurofibromas lesions (43). Usually, there are numerous neurofibromas with onset at different ages; some of them causing local pain and pruritus; a major impact regarding the quality of life is registered because of them $(42,44)$. No standard management has yet been considered, the approach varies from conservative to different procedures of removal including electrodessication (44).

The tumours with a higher risk in neurofibromatosis type 1 are benign or malignant such as gliomas of optic nerve, gastrointestinal stromal tumours (GISTs), somatostatinomas, and potentially adenocarcinomas of different origins $(37,39,45)$. An increased risk of breast cancer and leukaemia has been reported (41). Also, iris hamartomas, brain tumours and bone anomalies (including scoliosis) represent a specific configuration seen in neurofibromatosis type 1 which also increases the risk of learning and intellectual dysfunctions (46). Others morbidities such as peripheral nerve sheath malignancies, supranumerary teeth of permanent dentition, have been reported $(39,46)$.

These associated tumours require a multidisciplinary team involving a dermatologic, oncologic, surgical, orthopaedic, cardiovascular, gastrointestinal and endocrine approach in association with imaging and laboratory assessments. A certain level of heterogeneity is described even among individuals belonging to the same family (46). This represents a real challenge to practitioners following the subject's trough their lifespan despite the general level of awareness regarding the potential co-morbidities $(39,46)$. Of course, the challenge also is reflected by adequate and prompt interventional therapy for multiple neurofibromatosis type 1-associated disorders $(39,46)$. The most probable explanation of the phenotype variations of wide area is the gene that encodes neurofibromin 1 protein which was proven extremely heterogeneous, as well $(39,46)$. The tumour suppressor gene effects are different between various gene regions in addition to sex-hormones and germline influences $(39,46)$. Further gene targeted studies will help the clinicians to forecast the clinical complications and potentially to prevent them through gene manipulation. The importance of the topic is reflected by the relative high frequency of the disorder among inherited conditions.

The condition is distinct from neurofibromatosis type 2 which is an autosomal dominant disorder with NF2 tumour suppressor gene mutations on chromosome 22 (47-49). It is found in $1 / 25,000$ births $(48,49)$. The statistical data shows that by the age of 60 years the penetrance is almost $100 \%$; $50 \%$ of subjects inherit the mutation and $50 \%$ have acquired mutations $(48,49)$. The associated neoplasia with a high risk involves nervous central system such as schwannomas (especially bilateral vestibular location), astrocytomas, meningiomas, ependymomas and neurofibromas $(48,49)$. Moreover, the most frequent eye anomalies are cataract, retinal hamartomas, and epiretinal membranes $(48,49)$. Skin conditions found in neurofibromatosis type 2 are cutanous schwannomas and mild pattern of café-au-lait patches (not so frequent as in neurofibromatosis type 1) $(48,49)$. Other morbidities have been reported including malignant mesothelioma and sarcomas $(48,49)$. A multidisciplinary approach is needed as well as genetic counselling $(48,49)$.

Another disorder which is similar with type 1 and type 2 neurofibromatosis is schwannomatosis but it displays a distinct syndrome from type 1 and 2 neurofibromatosis (47-49). All three conditions together represent the class of neurofibromatoses with neurofibromatosis type 1 as the most frequent group (47-50).

\section{Somatostatinoma and neurofibromatosis type 1}

Neurofibromatosis type 1 is a complex and heterogeneous syndrome and the associated risk of neoplasia is sine qua non. The presence of a duodenal somatostatinoma has a higher risk than general population but this is not the most significant tumour association seen in patients with NF1 gene mutations. Duodenal somatostatinoma is associated with neurofibromatosis type 1 (which actually involves more often a duodenal tumour of GIST type and very rarely a somatostatin secreting neoplasia), and also with Von Hippel-Lindau syndrome or with tuberous sclerosis (4). Some reports include synchronous diagnosis of 
GIST and somatostatinoma in subjects with neurofibromatosis type 1, a combination called 'A triad worth remembering' by Njei and Sanchez (51). Hiesgen and Variava (52) reported for the first time a case of an HIV positive woman with a synchronous metastatic somatostatinoma and a gastrinoma presenting with diabetes mellitus, chronic diarrhoea and recurrent peptic ulcer. Somatostatinoma of ampulla of Vater and minor papilla has rarely been reported $(53,54)$. Neuroendocrine tumours other than somatostatinomas, for instance, gastrointestinal NENs at the level of rectum or jejunum have been reported in neurofibromatosis type $1(55,56)$. As mentioned, a subject with $N F 1$ gene mutations has a higher risk of pheocromocytoma in general population $(37,57)$. Overall, one quarter of patients with the syndrome have gastrointestinal tumours of different types (51).

\section{Discussion}

Three different aspects involving somatostatinoma without/without neurofibromatosis type 1 are discussed. One point of view includes current controversies; another is related to the body of evidence with a spectacular recent increase of NEN field, and also some genetic considerations as one more step to the future.

Controversies. There are still subjects regarding somatostatinoma that are a matter of debate or are not completely understood at present. The clinical picture at presentation might associate local compressive symptoms due to the tumour mass which are different between pancreatic and duodenal site. However, the symptoms strictly associate with hormonal excess are similar between the two main locations of the somatostatinoma and, unless there are local symptoms, there is no clue to specify the source. The general prognostic is poor despite the fact that somatostatinoma may be silent for a period of time. Which is the optimal approach is still inconclusive. Moreover, the specific prevalence of duodenal somatostatinoma in patients with neurofibromatosis type 1 is unknown; also the question related to the association with duodenal, not pancreatic site, is still unanswered (58). The use of first generation somatostatin analogues such as prolonged formulas of octreotide and lanreotide seems a paradox for a somatostatin secreting neoplasia but actually their role in tumour growth and function has been proven (59).

Neuroendocrine tumours. Somatostatinoma is part of a generous topic of neuroendocrine neoplasia. A large amount of publications are currently available since the progress of diagnosis and therapy has given an increasing trend to the subject. Gastroenteropancreatic neuroendocrine tumours represent the majority of NENs. The poor prognosis is related to non-rectal location, high grading (according to WHO criteria 2017 based on Ki67 proliferation marker and mitotic index), large tumour mass at diagnosis, metastases at any level including liver and bone, potential dedifferentiation processes in metastases involving a more aggressive profile than reflected by the primary lesion (60-62). Duodenal NENs underline this pattern as well as a potential curable approach based on surgery especially in early stages and in well differentiated NENs; if possible, less aggressive surgical approach decreases the risk of complications (63). The level of awareness improves the overall survival due to early recognition and therapy $(63,64)$. In this type of tumours the functional aspects are frequently positive thus the endocrine profile might help the early detection $(63,64)$. Opposite to non-neuroendocrine tumours, the neuroendocrine paraneoplastic syndromes are associated with both benign and malignant neoplasia and they do not necessarily represents a poor prognostic marker $(64,65)$. Somatostatinoma through the above mentioned presentation displays this scenario.

Genetic background. Both NENs and neurofibromatosis type 1 are related to genetic backgrounds which are known for neurofibromin 1 gene and less known as NEN implications for neurofibromatosis type 1. Loss of its function causes cells proliferation as contributor to different tumour formations $(66,67)$. The gene is difficult to be analysed because it is large and next-generation sequencing (NGS) seems promising to help the genetic diagnostic by covering the Ras-related signalling elements $(66,67)$. Novel variants of NF1 gene such as p.(Gln181Profs*20) have been recently reported (68). Aggressive breast cancer in females with neurofibromatosis type 1 involves germline mutations of neurofibromin 1 in association with other somatic mutations of TP53 or KMT2c (69). However, some of neoplasia associated mutations are described in non-neurofibromatosis cases (70-74).

\section{Conclusions}

Somatostatinoma, when not located on pancreas but in duodenum, may be registered in subjects with neurofibromatosis type 1 most probably in addition to other tumours. Overall, this type of neuroendocrine tumour with a challenging presentation has a poor prognosis unless adequate radical surgery is promptly offered to the patient.

\section{Acknowledgements}

Not applicable.

\section{Funding}

No funding was received.

\section{Availability of data and materials}

Not applicable.

\section{Authors' contributions}

FS critically revised the manuscript for its content and was involved in the conception of the study. MC wrote the manuscript and was involved in the conception of the study. AV was also involved in the conception of the study. SEA and RCP were responsible for the literature research and were involved in the conception of the study. MCD critically revised the manuscript and was involved in the conception of the study. All authors read and approved the final manuscript.

\section{Ethics approval and consent to participate}

Not applicable. 


\section{Patient consent for publication}

Not applicable.

\section{Competing interests}

The authors declare that they have no competing interests.

\section{References}

1. Williamson JM, Thorn CC, Spalding D and Williamson RC: Pancreatic and peripancreatic somatostatinomas. Ann R Coll Surg Engl 93: 356-360, 2011.

2. Zakaria A, Hammad N, Vakhariya C and Raphael M: Somatostatinoma presented as double-duct sign. Case Rep Gastrointest Med 2019: 9506405, 2019.

3. Wiesli P, Pavlicek V, Brändle M, Pfammatter T, Perren A and Schmid C: Distinct mechanisms of hypoglycaemia in patients with somatostatin-secreting neuroendocrine tumours. Endocrinol Diabetes Metab 2: e00083, 2019.

4. Thavaraputta S, Graham S, Rivas Mejia AM and Lado-Abeal J: Duodenal somatostatinoma presenting as obstructive jaundice with the coexistence of a gastrointestinal stromal tumour in neurofibromatosis type 1: A case with review of the literature. BMJ Case Rep 12: bcr-2018-226702, 2019.

5. Ambrose T, Stephenson TJ, Booth J and Chandra N: Case report: Recurrent acute pancreatitis secondary to papillary somatostatinoma - a new association. Pancreatology 13: 186-188, 2013.

6. Gheorghisan-Galateanu AA, Carsote M and Valea A: Incidentaloma: From general practice to specific endocrine frame. J Pak Med Assoc 67: 917-922, 2017

7. French JB and Pawa R: Somatostatinoma of the Ampulla: An incidental postoperative finding following colorectal cancer resection. ACG Case Rep J 3: 109-111, 2016.

8. Koc O, Duzkoylu Y, Sari YS, Bektas H, Uzum G, Tunali V and Pasaoglu E: Duodenal somatostatinoma: A case report and review of the literature. J Med Case Rep 7: 115, 2013.

9. Kanakis G and Kaltsas G: Biochemical markers for gastroenteropancreatic neuroendocrine tumours (GEP-NETs). Best Pract Res Clin Gastroenterol 26: 791-802, 2012.

10. Choe J, Kim KW, Kim HJ, Kim DW, Kim KP, Hong SM, Ryu JS, Tirumani SH, Krajewski K and Ramaiya $\mathrm{N}$ : What is new in the 2017 World Health Organization Classification and 8th American Joint Committee on cancer staging system for pancreatic neuroendocrine neoplasms? Korean J Radiol 20: 5-17, 2019.

11. Ito T, Igarashi $H$ and Jensen RT: Pancreatic neuroendocrine tumors: clinical features, diagnosis and medical treatment: advances. Best Pract Res Clin Gastroenterol 26: 737-753, 2012.

12. de Herder WW, Rehfeld JF, Kidd M and Modlin IM: A short history of neuroendocrine tumours and their peptide hormones. Best Pract Res Clin Endocrinol Metab 30: 3-17, 2016.

13. de Wilde RF, Edil BH, Hruban RH and Maitra A: Well-differentiated pancreatic neuroendocrine tumors: From genetics to therapy. Nat Rev Gastroenterol Hepatol 9: 199-208, 2012.

14. Ishida $\mathrm{H}$ and Lam AK: Pancreatic neuroendocrine neoplasms: The latest surgical and medical treatment strategies based on the current World Health Organization classification. Crit Rev Oncol Hematol 145: 102835, 2020.

15. Corleto VD: Somatostatin and the gastrointestinal tract. Curr Opin Endocrinol Diabetes Obes 17: 63-68, 2010.

16. Arrojo E Drigo R, Jacob S, García-Prieto CF, Zheng X, Fukuda M, Nhu HT, Stelmashenko O, Peçanha FL, Rodriguez-Diaz R, Bushong E, et al: Structural basis for delta cell paracrine regulation in pancreatic islets. Nat Commun 10: 3700, 2019.

17. Stengel A and Taché Y: Central somatostatin signaling and regulation of food intake. Ann NY Acad Sci 1455: 98-104, 2019.

18. Dumitrascu MC, Stanescu AM, Bejan C, Sandru F, Toader DO, Radavoi DG, Cotirlet A, Pusta CT and Diaconu CC: Obesity and its implications on stress urinary incontinence. Rev Chim (Bucharerst) 70: 3660-3662, 2019.

19. Silaghi AC,Poantă L, Valea A, Pais R and Silaghi H: Is epicardial adipose tissue, assessed by echocardiography, a reliable method for visceral adipose tissue prediction? Med Ultrason 13: 15-20, 2011.

20. Srivastava G and Apovian C: Future pharmacotherapy for obesity: New anti-obesity drugs on the horizon. Curr Obes Rep 7: 147-161, 2018.
21. Mansour JC and Chen H: Pancreatic endocrine tumors. J Surg Res 120: 139-161, 2004.

22. Mozell E, Stenzel P, Woltering EA, Rösch J and O'Dorisio TM: Functional endocrine tumors of the pancreas: Clinical presentation, diagnosis, and treatment. Curr Probl Surg 27: 301-386, 1990.

23. Nesi G, Marcucci T, Rubio CA, Brandi ML and Tonelli F: Somatostatinoma: Clinico-pathological features of three cases and literature reviewed. J Gastroenterol Hepatol 23: 521-526, 2008.

24. Prachayakul V, Aswakul P, Deesomsak M and Pongpaibul A: Gastric somatostatinoma: An extremely rare cause of upper gastrointestinal bleeding. Clin Endosc 46: 582-585, 2013.

25. DärrR,Nambuba J,Del RiveroJ,Janssen I,MerinoM,Todorovic M, Balint B, Jochmanova I, Prchal JT, Lechan RM, et al: Novel insights into the polycythemia-paraganglioma-somatostatinoma syndrome. Endocr Relat Cancer 23: 899-908, 2016.

26. Janssen I, Chen CC, Zhuang Z, Millo CM, Wolf KI, Ling A, Lin FI, Adams KT, Herscovitch P, Feelders RA, et al: Functional imaging signature of patients presenting with polycythemia/paraganglioma syndromes. J Nucl Med 58: 1236-1242, 2017.

27. Jochmanova I and Lazurova I: A new twist in neuroendocrine tumor research: Pacak-Zhuang syndrome, HIF-2 $\alpha$ as the major player in its pathogenesis and future therapeutic options. Biomed Pap Med Fac Univ Palacky Olomouc Czech Repub 158: 175-180, 2014.

28. Wang H, Cui J, Yang C, Rosenblum JS, Zhang Q, Song Q, Pang Y, Fang F, Sun M, Dmitriev P, et al: A transgenic mouse model of Pacak-Zhuang syndrome with an Epas1 gain-of-function mutation. Cancers (Basel) 11: 2019, 2019.

29. Pang Y, Gupta G, Jha A, Yue X, Wang H, Huynh TT, Li A, Li L, Baker E, Chew E, et al: Nonmosaic somatic HIF2A mutations associated with late onset polycythemia-paraganglioma syndrome: Newly recognized subclass of polycythemia-paraganglioma syndrome. Cancer 125: 1258-1266, 2019.

30. Vianna PM, Ferreira CR and de Campos FP: Somatostatinoma syndrome: A challenging differential diagnosis among pancreatic tumors. Autops Case Rep 3: 29-37, 2013.

31. Kim JA, Choi WH, Kim CN, Moon YS, Chang SH and Lee HR Duodenal somatostatinoma: A case report and review. Korean J Intern Med 26: 103-107, 2011.

32. Brelian D and Tenner S: Diarrhoea due to pancreatic diseases. Best Pract Res Clin Gastroenterol 26: 623-631, 2012

33. Jara Letelier DI, Bonotto ML and Ardengh JC: Somatostatinoma of the minor duodenal papilla associated with pancreas divisum treated by endoscopic papillectomy. Endoscopy 48 (Suppl 1): E135-E137, 2016.

34. Albulescu DM, Carsote M, Ionovici N, Ghemigian A, Popescu M, Tuculina MJ, Dascalu IT, Preda SA, Tirca T, Petrescu MS, et al: 5-Hydroxytriptamine and skeleton influence. Clinical study. Rev Chim (Bucharest) 69: 2438-2442, 2018.

35. Walczyk J and Sowa-Staszczak A: Diagnostic imaging of gastrointestinal neuroendocrine neoplasms with a focus on ultrasound. J Ultrason 19: 228-235, 2019.

36. Poiană C, Neamţu MC, Avramescu ET, Carşote M, Trifănescu R, Terzea D, Neamţu OM, Ferechide D and Dănciulescu Miulescu R: The poor prognosis factors in G2 neuroendocrine tumor. Rom J Morphol Embryol 54 (Suppl 3): 717-720, 2013.

37. Carşote M, Păun S, Neamţu MC, Avramescu ET, Iosif C, Terzea D, Constantinoiu S, Dănciulescu Miulescu R, Neamţu OM and Poiană C: The immunohistochemistry aspects in two cases of neurofibromatosis-associated abdominal tumors. Rom J Morphol Embryol 53: 401-405, 2012

38. Chan H, Moseley C, Zhang L, Bergsland EK, Pampaloni MH, Van Loon K and Hope TA: Correlation of DOTATOC uptake and pathologic grade in neuroendocrine tumors. Pancreas 48 : 948-952, 2019.

39. Przybylik-Mazurek E, Palen J, Pasternak-Pietrzak K, Sowa-Staszczak A, Brzozowska-Czarnek A and HubalewskaDydejczyk A: Coexistence of neurofibromatosis type 1 with multiple malignant neoplasia. Neuro Endocrinol Lett 39: 149-155, 2018.

40. Reynolds R and Marjoniemi V: Mixed mucinous adenocarcinoma and somatostatinoma of the ampulla of Vater associated with neurofibromatosis type 1. Pathology 49: 553-555, 2017.

41. Philpott C, Tovell H, Frayling IM, Cooper DN and Upadhyaya M: The NF1 somatic mutational landscape in sporadic human cancers. Hum Genomics 11: 13, 2017.

42. Hernández-Martín A and Duat-Rodríguez A: An update on neurofibromatosis type 1: Not just café-au-lait spots and freckling. Part II. Other skin manifestations characteristic of NF1. NF1 and cancer. Actas Dermosifiliogr 107: 465-473, 2016 (In English and Spanish). 
43. Rozza-de-Menezes RE, Brum CA, Gaglionone NC, de Sousa Almeida LM, Andrade-Losso RM, Paiva BV, Faveret PL, da Silva AV, Siqueira OH, Riccardi VM, et al: Prevalence and clinicopathological characteristics of lipomatous neurofibromas in neurofibromatosis 1: An investigation of 229 cutaneous neurofibromas and a systematic review of the literature. J Cutan Pathol 45: 743-753, 2018.

44. Lutterodt CG, Mohan A and Kirkpatrick N: The use of electrodessication in the treatment of cutaneous neurofibromatosis: A retrospective patient satisfaction outcome assessment. J Plast Reconstr Aesthet Surg 69: 765-769, 2016.

45. Afşar CU, Kara IO, Kozat BK, Demiryürek H, Duman BB and Doran F: Neurofibromatosis type 1, gastrointestinal stromal tumor, leiomyosarcoma and osteosarcoma: Four cases of rare tumors and a review of the literature. Crit Rev Oncol Hematol 86 191-199, 2013.

46. Anderson JL and Gutmann DH: Neurofibromatosis type 1. Handb Clin Neurol 132: 75-86, 2015.

47. Thomas AK, Egelhoff JC, Curran JG and Thomas B: Pediatric schwannomatosis, a rare but distinct form of neurofibromatosis Pediatr Radiol 46: 430-435, 2016.

48. Evans DG: Neurofibromatosis type 2. Handb Clin Neurol 132: 87-96, 2015.

49. Ardern-Holmes S, Fisher G and North K: Neurofibromatosis Type 2. J Child Neurol 32: 9-22, 2017.

50. Yamamoto R, Kato S, Maru T, Ninomiya R, Ozawa F, Beck Y, Abe K, Tamaru J, Nagoshi S and Yakabi K: The coexistence of somatostatinoma and gastrointestinal stromal tumor in the duodenum of a patient with Von Recklinghausen's disease. Intern Med 55: 617-622, 2016.

51. Njei B and Sanchez H: Education and imaging. Gastrointestinal Neurofibromatosis type 1 , duodenal somatostatinoma and gastrointestinal stromal tumors; a triad worth remembering. J Gastroenterol Hepatol 29: 663, 2014

52. Hiesgen $J$ and Variava E: Neuroendocrine tumour in a patient with neurofibromatosis type 1 and HIV. South Afr J HIV Med 16: $323,2015$.

53. Bhandari R, Riddiough G, Lokan J, Weinberg L, Efthymiou M and Nikfarjam M: Somatostatinoma of the minor papilla treated by local excision in a patient with neurofibromatosis type 1 . JOP 16: 81-84, 2015

54. Tewari N, Rollins K, Gandhi N, Kaye P and Lobo DN: Mixed periampullary adenocarcinoma and somatostatinoma with small bowel gastrointestinal stromal tumour in neurofibromatosis type 1. JOP 15: 600-603, 2014

55. Xie R, Fu KI, Chen SM, Tuo BG and Wu HC: Neurofibromatosis type 1-associated multiple rectal neuroendocrine tumors: A case report and review of the literature. World J Gastroenterol 24 $3806-3812,2018$

56. Constantinoiu S, Constantin A,Predescu D, IosifC, Hoara P, AchimF Surugiu P, Bacanu F and Cociu L: Somatostatinoma of the first jejunal loop in a patient with neurofibromatosis von Recklinghausen and bilateral pheochromocytoma. Hepatogastroenterology 59: 1874-1878, 2012

57. Pan D, Liang P and Xiao H: Neurofibromatosis type 1 associated with pheochromocytoma and gastrointestinal stromal tumors: A case report and literature review. Oncol Lett 12: 637-643, 2016.

58. Cimino PJ and Gutmann DH: Neurofibromatosis type 1. Handb Clin Neurol 148: 799-811, 2018.

59. Bundschuh RA, Habacha B, Lütje S and Essler M: Therapy of patients with neuroendocrine neoplasia-evidence-based approaches and new horizons. J Clin Med 8: E1474, 2019.

60. Huang PY, Tsai KL, Liang CM, Tai WC, Rau KM, Wu KL, Huang CC and Chuah SK: Prognostic factors of patients with gastroenteropancreatic neuroendocrine neoplasms. Kaohsiung J Med Sci 34: 650-656, 2018
61. Poiană C, Neamtu MC, Avramescu ET, Carsote M, Trifănescu R, Terzea D, Neamţu OM and Dănciulescu Miulescu R: The dedifferentiation of neuroendocrine tumor metastases: Myth or reality? Rom J Morphol Embryol 54: 201-203, 2013.

62. Poiană C, Carşote M, Neamţu MC, Avramescu ET, Vasilescu F, Terzea D, Păun D, Trifănescu R and Dănciulescu Miulescu R: Well-differentiated neuroendocrine tumor and osteoporosis: Incidental findings? Rom J Morphol Embryol 54: 1169-1171, 2013

63. Untch BR, Bonner KP, Roggin KK, Reidy-Lagunes D, Klimstra DS, Schattner MA, Fong Y, Allen PJ, D'Angelica MI, DeMatteo RP, et al: Pathologic grade and tumor size are associated with recurrence-free survival in patients with duodenal neuroendocrine tumors. J Gastrointest Surg 18: 457-462, discussion 462-463, 2014

64. Guilmette J and Nosé V: Paraneoplastic syndromes and other systemic disorders associated with neuroendocrine neoplasms. Semin Diagn Pathol 36: 229-239, 2019.

65. Paun DL, Vija L, Stan E, Banica A, Bobeica E, Terzea D, Poiana C, Badiu C and Paun S: Cushing syndrome secondary to ectopic adrenocorticotropic hormone secretion from a Meckel diverticulum neuroendocrine tumor: Case report. BMC Endocr Disord 15: 72, 2015.

66. Pasmant E, Parfait B, Luscan A, Goussard P, Briand-Suleau A Laurendeau I, Fouveaut C, Leroy C, Montadert A, Wolkenstein P, et al: Neurofibromatosis type 1 molecular diagnosis: What can NGS do for you when you have a large gene with loss of function mutations? Eur J Hum Genet 23: 596-601, 2015.

67. Wu-Chou YH, Hung TC, Lin YT, Cheng HW, Lin JL, Lin CH, Yu CC, Chen KT, Yeh TH and Chen YR: Genetic diagnosis of neurofibromatosis type 1: Targeted next-generation sequencing with multiple ligation-dependent probe amplification analysis. J Biomed Sci 25: 72, 2018.

68. Xu G, Li M, Niu Y, Huang X, Li Y, Tang G, Long S, Zhao H and Jiang $\mathrm{H}$ : Identification of a novel NF1 frameshift variant in a Chinese family with neurofibromatosis type 1 . BioMed Res Int 2019: 2721357, 2019.

69. Yap YS, Munusamy P, Lim C, Chan CH, Prawira A, Loke SY, Lim SH, Ong KW, Yong WS, Ng SB, et al: Breast cancer in women with neurofibromatosis type 1 (NF1): A comprehensive case series with molecular insights into its aggressive phenotype. Breast Cancer Res Treat 171: 719-735, 2018

70. Solomon I, Voiculescu VM, Caruntu C, Lupu M, Popa A, Ilie MA, Albulescu R, Caruntu A, Tanase C, Constantin C, et al: Neuroendocrine factors and head and neck squamous cell carcinoma: An affair to remember. Dis Markers 2018: 9787831 , 2018.

71. Ion A, Popa IM, Papagheorghe LM, Lisievici C, Lupu M, Voiculescu V, Caruntu C and Boda D: Proteomic approaches to biomarker discovery in cutaneous T-cell lymphoma. Dis Markers 2016: 9602472, 2016.

72. Boda D: Cellomics as integrative omics for cancer. Curr Proteomics 10: 237-245, 2013.

73. Ilie MA, Caruntu C, Lupu M, Lixandru D, Tampa M, Georgescu SR, Bastian A, Constantin C, Neagu M, Zurac SA, et al: Current and future applications of confocal laser scanning microscopy imaging in skin oncology. Oncol Lett 17: 4102-4111, 2019.

74. Căruntu C, Boda D, Guţu DE and Căruntu A: In vivo reflectance confocal microscopy of basal cell carcinoma with cystic degeneration. Rom J Morphol Embryol 55: 1437-1441, 2014. 